\section{Management of Type III Dens Invaginatus in a Mandibular Premolar: A Case Report}

Fabiana Vieira Vier-Pelisser ${ }^{1}$, Renata Dornelles Morgental ${ }^{1}$, Guilherme Fritscher ${ }^{2}$, Alexandre Correa Ghisi ${ }^{1}$, Maristela Gutiérrez de Borba ${ }^{1}$, Roberta Kochenborger Scarparo ${ }^{1}$

\author{
'Department of Endodontics, School \\ of Dentistry, PUCRS - Pontifical \\ Catholic University of Rio Grande \\ do Sul , Porto Alegre, RS, Brazil \\ ${ }^{2}$ Department of Oral Surgery, School \\ of Dentistry, PUCRS - Pontifical \\ Catholic University of Rio Grande \\ do Sul, Porto Alegre, RS, Brazil
}

Correspondence: Profa. Dra. Renata Dornelles Morgental, Avenida lpiranga, 6681, Prédio 6, 90619-900 Porto Alegre, RS, Brasil. Tel.: +55-513320-3538/+55-51-9722-6669. e-mail: remorgental@hotmail.com
Dens invaginatus is a well-known malformation of teeth, which probably results from an invagination of enamel organ into dental papilla during tooth development. The endodontic treatment of invaginated teeth may be challenging due to difficulties in accessing the root canals and also due to complex variations of internal morphology. This article presents the endodontic management and follow-up in a rare case of right mandibular second premolar with Oehlers' type III dens invaginatus. The result of cold pulp testing was positive for this tooth but it was associated to a sinus tract and periapical lesion. Herein, it is described the root canal therapy of this tooth combined with periapical surgery, emphasizing the importance of proper diagnosis and planning by using cone beam computed tomography (CBCT). This case report presents the proper periapical healing 6 months after the combination of nonsurgical and surgical treatments. It also shows that CBCT is an important auxiliary examination to avoid errors in diagnosis and subsequent treatment of dental anomalies.
Key Words: cone beam computed tomography, dens invaginatus, endodontic treatment, endodontic surgery, mandibular premolar.

\section{Introduction}

Dens invaginatus (DI), also known as 'dens in dente', is a dental anomaly marked as an early invagination of enamel and dentine that may extend deep into the pulp cavity and to the roots, sometimes reaching the apex (1). The reported prevalence of permanent teeth affected with $\mathrm{DI}$ is variable, ranging from $0.3 \%$ to $10 \%$, due to methodological differences in the cohorts studies, identification criteria used and diagnostic difficulties (2). The most commonly affected tooth is the maxillary lateral incisor (1). This condition may coexist with other anomalies, such as talon cusps (3). DI rarely occurs in mandibular posterior teeth, extending from the occlusal pit. Few cases have been reported in mandibular premolars (4-6).

The degree of malformation associated with $\mathrm{DI}$ has been classified by Oehlers (7) into three categories and this classification system is the most used worldwide. Type I represents a minor invagination, lined by enamel, not extending beyond the cementum-enamel junction. In Type II, the enamel-lined anomaly invades the root but remains as a blind sac; it may communicate or not with the dental pulp. In Type III, the invagination penetrates through the root, reaching the apical area and a second foramen emerges in the periodontium. There is no immediate communication with the pulp. The invagination may be completely lined by enamel, but frequently cementum will be found in the invagination.
Clinically, DI presents unusual crown morphology, but affected teeth may also show no clinical signs of malformation. The invagination allows entry of irritants into an area that is separated from pulp tissue by only a thin layer of enamel and dentine (1). It may predispose to the development of dental caries and subsequent pulp inflammation. The affected pulp tissue frequently undergoes necrosis.

In cases in which DI is not associated with any pathological signs, it is important to formulate a plan of prevention and follow up over time. Conservative treatment is indicated for teeth that belong to Type I and for some forms of teeth belonging to Type II, whereas endodontic therapy is the treatment of choice for DI Type III and for other types in which the infection has spread, causing pulp necrosis (8). Some authors have dealt with the presence of wide apical foramen associated with DI and apical periodontitis (9-11) using mineral trioxide aggregate (MTA) to fill the apical portion of the canal. Surgery is the most usual treatment in the most severe forms of Type III because cleaning and shaping procedures may be particularly difficult because of the anatomic variations (12-14). Extraction is indicated only in teeth with extreme anatomic irregularities that cannot be surgically treated and supernumerary teeth with DI (8).

For many decades, imaging in Endodontics was limited to two-dimensional, conventional intraoral radiographs. 
Recently, the advent of cone beam computed tomography (CBCT), a three-dimensional (3D) imaging modality, has helped in diagnosis and better treatment planning of complex cases requiring endodontic therapy, such as DI $(15,16)$.

CBCT uses low effective radiation dose and was designed to generate undistorted $3 \mathrm{D}$ reconstruction of the maxillofacial skeleton, including images of teeth and their surrounding tissues (17). Periapical disease may be detected sooner using CBCT compared to periapical radiographs, revealing the actual size, nature and position of periapical and resorptive lesions. In addition, CBCT scans provide important information about dental anatomy and can be used prior to endodontic surgery to assess inclination of roots and bone thickness (18).

The purpose of this article is to report a case of $D I$ in a permanent mandibular second premolar with vital pulp, but associated with a sinus tract and periapical lesion, which required a combination of nonsurgical and surgical treatments. It is also emphasizes the importance of CBCT in the diagnosis and treatment planning.

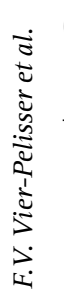

\section{Case Report}

This study was approved by the Ethics Committee of the Pontifical Catholic University of Rio Grande do Sul
(PUCRS), Brazil (Registration \#228.942/2013). The patient's legal guardian signed an informed consent.

An 11-year-old boy was admitted to the Department of Endodontics at PUCRS, Brazil, presenting a vestibular sinus tract in the periapical area around the mandibular right second premolar. Radiographic tracking with a gutta-percha point revealed its origin to be in the wide-open apical end of an invaginated canal of this tooth (Fig. 1A). The anomalous internal structure was consistent with Oehlers' Type III dens invaginatus. Clinically, this tooth showed an unusual coronal anatomy, with greater mesiodistal width, normal color, normal gingival tissues and probing depth $(<3 \mathrm{~mm})$, and deficient composite resin restoration on the occlusal surface (Fig. 1B). Radiographic examination of the contralateral tooth did not reveal malformation.

Review of medical history was unremarkable, but the dental history revealed an excisional biopsy in the same region 10 months before. The patient brought his former dental reports and radiographs. They showed an extensive periradicular lesion measuring $3.0 \times 1.8 \mathrm{~cm}$ associated with the mandibular right first and second premolars and first molar (Fig. 1C). On that occasion, the response to pulp sensitivity test (EndoFrost, Roeko, Langenau, Germany) was positive for mandibular right first and second premolars, negative to the mandibular right first molar
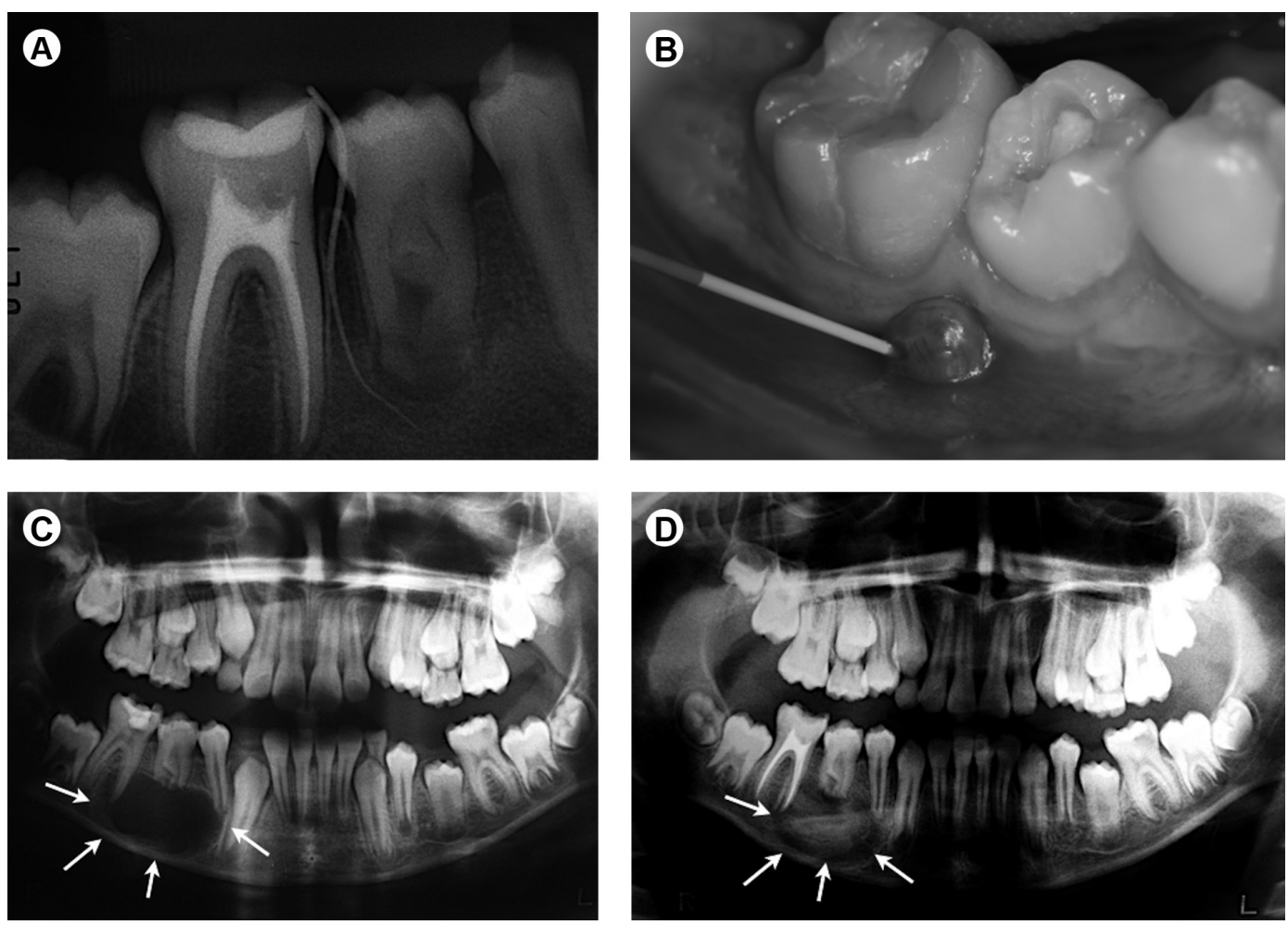

Figure 1. (A and B) Clinical aspect and radiographic tracking with a gutta-percha point. Periapical lesion originated in the wide-open apical end of an Oehlers' Type 111 dens invaginatus in the right mandibular second premolar. (C) A former dental radiography, taken 10 months before, reveals an extensive periradicular lesion (arrows) associated with the mandibular right first and second premolars and first molar. (D) Radiographic examination 4 months after root canal treatment in mandibular right first molar and excisional biopsy shows ongoing periapical repair (arrows). 
and the patient was asymptomatic. Root canal treatment of the mandibular right first molar and excisional biopsy were performed. Radiographic examination 4 months postoperatively showed ongoing periapical repair (Fig. 1D).
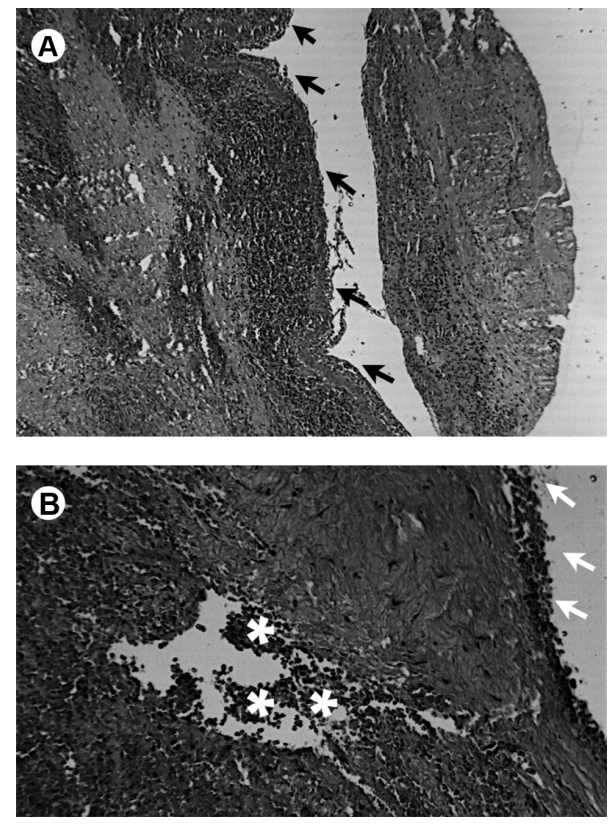

Figure2.(A)Histopathologicalsectionsshowa cysticcavitylined withstratified squamous epithelium (arrows) and intense and diffuse inflammatory infiltrate composed of polymorphonuclear neutrophils and mononuclear cells - HE; original magnification 100x. (B) Greater magnification (200x) of an abscessed area (asterisks) close to the epithelium layer (arrows).

Histopathological diagnosis was consistent with abscessed cyst (Fig. 2).

Considering the past dental history, a cone beam computed tomography (CBCT) scan of the involved teeth was performed as a complementary examination (i-CAT CBCT Scanner; Imaging Sciences International Inc, Hatfield, PA, USA), at $120 \mathrm{kVp}$, in 1.0-mm thick sections. The CBCT scans (Fig. 3) revealed two root canals in the mandibular right second premolar: the main canal located lingually, which tapered progressively towards the apex and appeared to be apically closed, presenting a half-moon or C-shaped conformation; and an obliterated invaginated buccal canal in the cervical third, which became wide-open at the exit portal in the middle third, associated with periapical lesion and discontinuous buccal cortical plate. The invaginated canal seemed to be lined by enamel. It was not possible to identify any communication between the main and the invaginated canals in the axial scan, despite the close proximity between them.

At this moment, a decision was made to perform endodontic treatment in the mandibular right second premolar, followed by paraendodontic surgery. Thus, after local anesthesia and rubber dam isolation, an occlusal access cavity was prepared. The pulp vitality was evident and there was only a trace of one opening within the crown chamber merging into one large $\mathrm{C}$-shaped canal, localized more lingually. Root canal working length $(20 \mathrm{~mm})$ was radiographically established $1 \mathrm{~mm}$ short of the apex. Considering its C-shaped configuration, the main canal was first

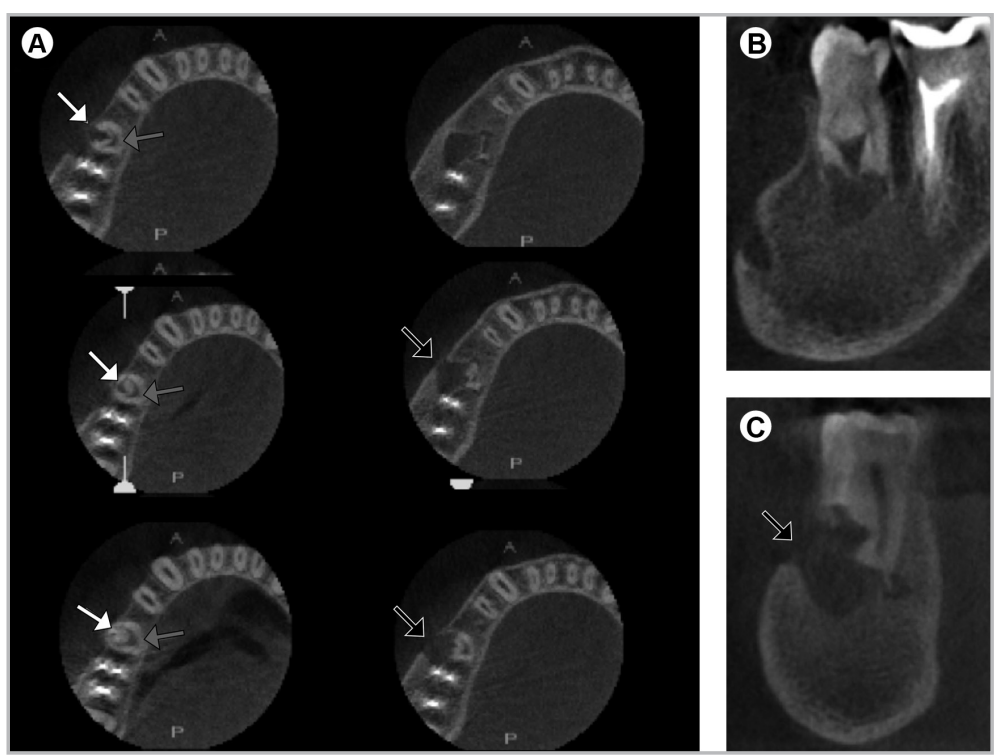

Figure 3. Cone beam computed tomography (CBCT): axial (A), sagittal (B) and coronal (C) sections. The mandibular right second premolar presents an anatomy corresponding to Oehlers' Type 111 dens invaginatus with two independent canals. An invaginated buccal canal (white arrows) with wide apical opening was associated with periapical lesion and discontinuous buccal cortical plate (black arrows). The main canal (gray arrows) was located lingually, presenting a half-moon or C-shaped conformation. explored with size $15 \mathrm{~K}$-files (anatomical diameters) in three different points (Fig. $4 \mathrm{~A})$. It was instrumented according to a crown-down technique up to size 30 K-Flexofile hand instruments (DentsplyMaillefer, Ballaigues, Switzerland), followed by step-back preparation from the working length at $1 \mathrm{~mm}$ increments up to a \#50 size. Throughout the preparation, this canal was copiously irrigated with $2.0 \%$ sodium hypochlorite (Virex; Johnson Diversey, Sturtevant, WI, USA) and flushed with 17\% EDTA (Biodinâmica, Ibiporã, PR, Brazil). After drying with paper points, the canal was filled with calcium hydroxide paste (Calen; S.S. White, Rio de Janeiro, RJ, Brazil) and sealed with provisional cement.

Unfortunately, the patient returned to appointment only 5 months later, presenting maintenance of sinus tract and reporting acute symptoms during this period. The main canal was re-prepared up to size 40 
K-Flexofile hand instruments and medicated once again with calcium hydroxide paste. After one month, this canal was filled with lateral condensation, using three \#40 gutta-percha master points (Tanari, Manaus, AM, Brazil) with cut ends, gutta-percha accessory points and AH Plus sealer (Dentsply DeTrey, Kontanz, Germany), as shown in Fig. 4B. After obturation, the presence of gaps could be verified in the apical third (Fig. $4 \mathrm{C}$ ). The access cavity was sealed with glass ionomer cement (Vidrion R; S.S. White).

Endodontic surgery was performed in a subsequent session. After local anaesthesia with 4\% articaine (DFL,
Rio de Janeiro, RJ, Brazil), incision and elevation of a full-thickness flap, the lesion involving the wide-open invaginated canal was curetted. After ostectomy in direction to the lingual plate, the apical region of the main canal was reached and curetted, followed by rootend resection (Fig. 4D). Cavity preparation was carried out with ultrasonic tips followed by orthograde filling of both canals (main and invaginated) with white MTA (Angelus, Londrina, PR, Brazil). The flap was repositioned, sutured with 4.0 nylon sutures (Ethicon; Johnson \& Johnson, Sao Paulo, SP, Brazil) and an immediate postoperative periapical
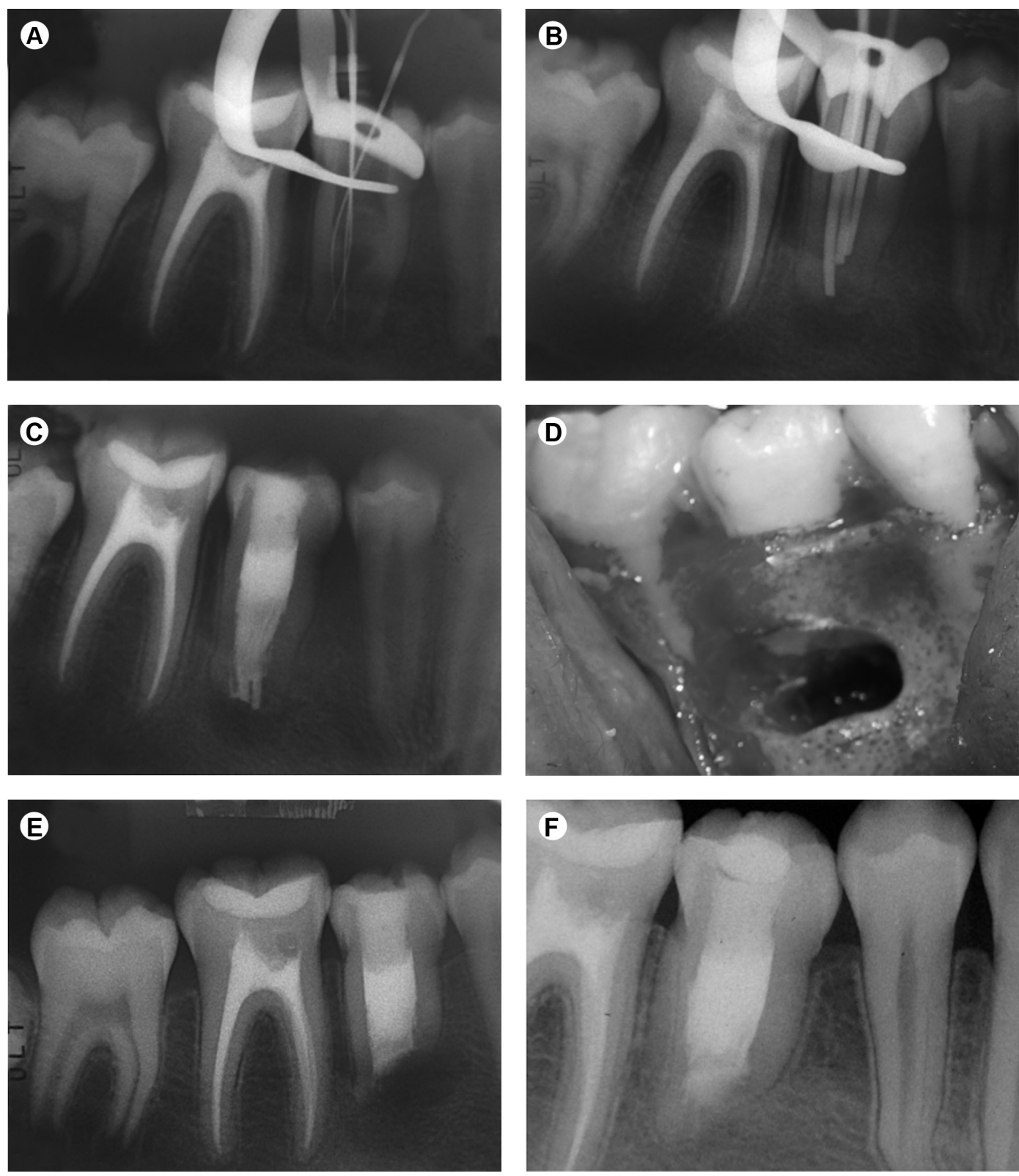

Figure 4. (A) Radiograph for working length determination with three K-files in the C-shaped main canal. (B) Pre-obturation radiograph with three gutta-percha master cones. (C) Radiographic aspect after nonsurgical root canal treatment. Surgical cavity (D) and radiograph (E) following root-end resection and orthograde filling with white MTA. (F) Periapical repair after 6 months. 
radiograph was taken (Fig. 4E). The patient was systemically treated with amoxicillin plus clavulanate $(500 / 125 \mathrm{mg}$, $8 / 8 \mathrm{~h}$ for 7 days), ibuprofen ( $600 \mathrm{mg}, 12 / 12 \mathrm{~h}$ for 5 days) and acetaminophen (750 mg, 6/6 $\mathrm{h}$ for 5 days). Sutures were removed one week later. Radiographic examination 6 months postoperatively (Fig. 4F) showed periapical repair and the patient remained symptom-free.

\section{Discussion}

This article presents an interesting case of Oehlers' Type III DI in a right mandibular second premolar. Occurrence of $\mathrm{DI}$ in the mandibular premolar region is a rare clinical finding (6). Two root canals were identified in the tooth: a main canal with vital pulp tissue and an invaginated canal with necrotic tissue, which was associated with a periapical lesion. As verified in axial CBCT sections, the main canal was $C$-shaped and located lingually. It seemed like the pulp was compressed by the invagination (2). C-shaped canals represent a great challenge in Endodontics, so that different preparation techniques have been suggested to facilitate debridement, as well as different obturation techniques to fill the irregular and narrow pulp space (19).

Former dental reports revealed a previous excisional biopsy in the same area, although no endodontic intervention had been performed in this particular tooth, only in the adjacent first molar. The second premolar was responsive to the pulp sensitivity test and a CBCT scan was not requested on that occasion. Probably owing to these aspects, a mistaken treatment plan was carried out and led to a reintervention in that area a few months later.

It is noteworthy that thermal and electrical pulp tests have inherent limitations. These methods indicate only the vitality of the pulpal sensory supply, but the vascular supply is more important for the determination of pulp health. Limitations are particularly noted in multi-rooted teeth with vital pulp in at least one canal and necrotic pulp in the rest of the root canal system; they may provide a sensitive reaction in thermal and electrical tests (20). A similar situation occurred in the present case.

Despite pulp sensitivity to the tests, a sinus tract developed in the gingiva, originated from a remaining periapical lesion in the second premolar. The lack of communication between the vital pulp tissue in the main canal and the necrotic tissue in the invaginated canal explained the positive response to pulp testing. There was a deficient composite resin restoration on the occlusal surface, thus the presence of caries in this region could have led to bacterial penetration through the irregularly structured and hypomineralized enamel, into the invaginated canal, causing chronic apical periodontitis (1). Another explanation for the development of periapical disease associated with invaginated canals was proposed by De Smit et al. (21) and considered in previous case reports (15). They performed an exceptional histological investigation of impacted maxillary incisors with invaginations. In the apical region, ameloblasts were oriented in a columnar cell layer with a large central area composed of connective tissue, which was richly supplied with blood vessels observed from the superficial infolding to the depth of the invagination. After eruption, teeth with DI would lose this blood supply to the tissues in the invaginated space, with subsequent tissue necrosis.

The complex anatomy of teeth with Type III DI makes conventional endodontic treatment challenging, especially in cases with wide apical opening. Although conservative root canal treatment of Type III DI is possible in some cases $(11,22-24)$, the combination of nonsurgical and surgical endodontic procedures was necessary in the present case $(15,25)$. This approach was chosen because it was not possible to locate the invaginated canal through the coronal access cavity, even under magnification using a dental operating microscope, and also because the canal had an unusual conformation with a wide apical opening. Some authors reported the aid of a microscope in the location of the abnormal canal in the cervical region (24). However, this was not possible in the present case, and due to the risk of lateral perforation with burs, conventional access to the invaginated canal was not attempted.

The use of MTA as a filling material is becoming popular in cases of DI, due to its advantageous characteristics, such as sealing capacity, biocompatibility and apical healing stimulation $(11,25)$. The so-called "one-step apexification technique" with MTA is an interesting alternative to successive changes of calcium hydroxide dressing (24). In the present case, there was no coronal access to the invaginated canal, so MTA was employed as a retrofilling material after surgical access.

Some authors have stated that endodontic treatment of the main canal is not necessary if there is no connection with the invaginated canal or when pulp necrosis is not detected (23). In the case reported herein, CBCT revealed two separate canals. Nevertheless, endodontic treatment of the primary canal was performed because rupture of its neurovascular bundle could occur during surgery, causing necrosis and a doubtful prognosis. Interestingly, no damage happened during the first surgical intervention (excisional biopsy), and the pulp tissue within the primary canal remained vital. However, in this second surgical intervention, apical access and preparation of the invaginated canal was intended, so the risk of neurovascular damage was high.

CBCT was an important auxiliary tool in this case. CBCT scans revealed that the invagination was narrow in the coronal third and lined by enamel, which made it difficult to reach the invaginated canal via coronal access. During 
retropreparation, the tactile feeling and the sound produced by the ultrasonic tip were not consistent with dentin. Using $\mathrm{CBCT}$, it was also possible to determine that the periapical lesion produced discontinuity of the buccal cortical plate.

CBCT was used as a diagnostic tool only in the initial phase of the treatment. Postoperative control was performed with conventional dental radiographs. They revealed periapical repair at the six-month recall, the patient remained asymptomatic and the sinus tract had healed completely, attesting clinical success.

It is well known that CBCT offers several advantages over conventional radiography. However, rigorous indication of use should be respected to determine, on a case-by-case basis, if CBCT imaging will add meaningful information to diagnosis and treatment in view of the patient's best interest. Full adherence to the 'as low as reasonably achievable' (ALARA) radiation dose concept is mandatory to select the most appropriate radiological technique for each case.

In conclusion, pulp sensitivity tests should be interpreted with caution in cases of Type III DI, since the invaginated canal may have no communication with the main canal. The use of CBCT was an important tool to define the actual extension of the periapical lesion and provided relevant details of the internal anatomy of this invaginated tooth. Also, the combination of nonsurgical and surgical treatments was an effective approach in this case.

\section{Resumo}

Dens invaginatus é uma malformação dentária já bem reconhecida, que provavelmente resulta de uma invaginação do órgão do esmalte para dentro da papila dentária durante o desenvolvimento do dente em questão. 0 tratamento endodôntico de dentes invaginados pode ser um desafio devido às dificuldades de acesso aos canais radiculares e também devido à complexidade da morfologia interna. Este artigo apresenta o manejo endodôntico e o acompanhamento de um caso raro de segundo pré-molar inferior direito com dens invaginatus Tipo III de Oehlers. 0 resultado do teste de sensibilidade pulpar ao frio foi positivo para este dente, mas o mesmo estava associado a uma fístula e lesão periapical. Relata-se o tratamento de canal deste dente associado à cirurgia periapical, enfatizando a importância de um correto diagnóstico e plano de tratamento, utilizando a tomografia computadorizada de feixe cônico (TCFC). Este relato de caso mostra reparo periapical adequado 6 meses após a combinação dos tratamentos não-cirúrgico e cirúrgico. Mostra também que a TCFC é um importante exame auxiliar para evitar erros no diagnóstico e posterior tratamento de anomalias dentárias.

\section{References}

1. Hulsmann M. Dens invaginatus: aetiology, classification, prevalence, diagnosis, and treatment considerations. Int Endod J 1997;30:79-90.

2. Alani A, Bishop K. Dens invaginatus. Part 1: classification, prevalence and aetiology. Int Endod J 2008;41:1123-1136.

3. Nagaveni NB, Umashanikara KV, Vidyullatha BG, Sreedevi S, Radhika NB. Permanent mandibular incisor with multiple anomalies - report of a rare clinical case. Braz Dent J 2011;22:346-350.
4. Bramante CM, de Sousa SM, Tavano SM. Dens invaginatus in mandibular first premolar. Oral Surg Oral Med Oral Pathol 1993;76:389.

5. Hartup GR. Dens invaginatus type III in a mandibular premolar. Gen Dent 1997;45:584-587.

6. Canger EM, Kayipmaz S, Celenk P. Bilateral dens invaginatus in the mandibular premolar region. Indian J Dent Res 2009;20:238-240.

7. Oehlers FA. Dens invaginatus (dilated composite odontome). I. Variations of the invagination process and associated anterior crown forms. Oral Surg Oral Med Oral Pathol 1957;10:1204-1218 contd.

8. de Sousa SM, Bramante CM. Dens invaginatus: treatment choices. Endod Dent Traumatol 1998;14:152-158.

9. Steffen $H$, Splieth $C$. Conventional treatment of dens invaginatus in maxillary lateral incisor with sinus tract: one year follow-up. J Endod 2005;31:130-133.

10. Sathorn C, Parashos P. Contemporary treatment of class II dens invaginatus. Int Endod J 2007;40:308-316.

11. Demartis P, Dessi C, Cotti M, Cotti E. Endodontic treatment and hypotheses on an unusual case of dens invaginatus. J Endod 2009;35:417-421.

12. Beltes P. Endodontic treatment in three cases of dens invaginatus. J Endod 1997;23:399-402.

13. Nallapati S. Clinical management of a maxillary lateral incisor with vital pulp and type 3 dens invaginatus: a case report. J Endod 2004;30:726731.

14. Chaniotis AM, Tzanetakis GN, Kontakiotis EG, Tosios KI. Combined endodontic and surgical management of a mandibular lateral incisor with a rare type of dens invaginatus. J Endod 2008;34:1255-1260.

15. Vier-Pelisser FV, Pelisser A, Recuero LC, So MV, Borba MG, Figueiredo JA. Use of cone beam computed tomography in the diagnosis, planning and follow up of a type III dens invaginatus case. Int Endod J 2012;45:198-208.

16. Kfir A, Telishevsky-Strauss Y, Leitner A, Metzger Z. The diagnosis and conservative treatment of a complex type 3 dens invaginatus using cone beam computed tomography (CBCT) and 3D plastic models. Int Endod J 2013;46:275-288.

17. Al-Rawi $B$, Hassan $B$, Vandenberge $B$, Jacobs R. Accuracy assessment of three-dimensional surface reconstructions of teeth from cone beam computed tomography scans. J Oral Rehabil 2010;37:352-358.

18. Patel S, Dawood A, Ford TP, Whaites E. The potential applications of cone beam computed tomography in the management of endodontic problems. Int Endod J 2007;40:818-830.

19. Jafarzadeh $\mathrm{H}, \mathrm{Wu} \mathrm{YN}$. The $\mathrm{C}$-shaped root canal configuration: a review. J Endod 2007;33:517-523.

20. Jafarzadeh $\mathrm{H}$, Abbott PV. Review of pulp sensitivity tests. Part I: general information and thermal tests. Int Endod J 2010;43:738-762.

21. De Smit A, Jansen HW, Dermaut L. An histological investigation of invaginated human incisors. J Biol Buccale 1984;12:201-209.

22. Chen YH, Tseng CC, Harn WM. Dens invaginatus. Review of formation and morphology with 2 case reports. Oral Surg Oral Med Oral Pathol Oral Radiol Endod 1998;86:347-352.

23. Goncalves A, Goncalves M, Oliveira DP, Goncalves N. Dens invaginatus type III: report of a case and 10-year radiographic follow-up. Int Endod J 2002;35:873-879.

24. Jung M. Endodontic treatment of dens invaginatus type III with three root canals and open apical foramen. Int Endod J 2004;37:205-213.

25. Reddy YP, Karpagavinayagam K, Subbarao CV. Management of dens invaginatus diagnosed by spiral computed tomography: a case report. J Endod 2008;34:1138-1142. 